๑ Entomologica Fennica. 8 May 2000

\title{
Post-embryonic development of the lateral eye of Cloeon sp. (Ephe- meroptera: Baetidae) as revealed by scanning electron microscopy
}

\author{
Susmita Gupta, Abhik Gupta \& V.Benno Meyer-Rochow*
}

Gupta, S., Gupta, A. \& Meyer-Rochow, V. B. 2000: Post-embryonic development of the lateral eye of Cloeon sp. (Ephemeroptera: Baetidae) as revealed by scanning electron microscopy. — Entomol. Fennica 11: 89-96.

Post-embryonic developmental patterns of the lateral eyes of both male and female Cloeon sp. are described and compared with each other morphometrically on the basis of scanning electron microscopy. In the larvae number of ommatidia, ommatidial size, and total corneal surface area of the eye increase towards the subimaginal moult. It is then that clear differences between males and females begin to occur: while further increases in the number of ommatidia are recorded from the lateral eye of subimago and imago females (accompanied by decreasing facet sizes and interommatidial angles), males show decreasing numbers of ommatidia and total corneal areas in their lateral eyes as they prepare to leave the water. Consequently, the lateral eyes of a female are larger than those of a male imago. It appears that the enormous development of the dorsal eyes of the males has occurred at the expense of the lateral eyes. In male as well as female lateral eyes two major facet shapes are encountered: squares with rounded corners which are predominantly found in the central and upward looking areas, and hexagons which are dominating the lateral and ventral-facing regions. The different roles of the lateral eyes in male and female baetid mayflies is discussed in relation to their flights and the intriguing idea is presented that females might choose males with the largest dorsal eyes.

Susmita Gupta, Regional Sophisticated Instrumentation Centre, Bijni Complex, North Eastern Hill University, Shillong, Meghalaya, 793003 India

Abhik Gupta Department of Ecology, Assam University, P.B. No. 63, Silchar, Assam, 788015 India

V.Benno Meyer-Rochow, Department of Biology, FIN-90014 University of Oulu, Finland; e-mailvmr@sun3.oulu.fi

Received 1 June 1999, accepted 13 October 1999

\section{Introduction}

Mayflies (Ephemeroptera) are an important com- ponent of the ecology of many boreal as well as high altitude freswater systems and represent excellent material for investigations on the effects

*Corresponding author and present address:

Institute of Arctic Medicine, University of Oulu, Aapistie 1, FIN-90014 University of Oulu, Finland, (e-mail: vmr@cc.oulu.fi) 
of aquatic pollution and ecological inter-relationships (Cummins 1973, Merritt et al. 1984). However, because of their unique features and unusual development they are also extremely valuable for functional and morphological studies. The present paper deals with the post-embryonic development of the eyes of a species of baetid mayfly that has already been the subject of an earlier SEM-study of the sensilla (Gupta et al. 1999).

The eyes, being photoreceptive organs, can be expected to perceive changes in brightness and to serve as instruments in both nymphs and adults for estimating form, shape, and distance. Furthermore, they help (a) the adult males recognize females (usually against the sky in dim light) and (b) the mature females to visually locate watersurfaces from the air by "polarotaxis" (Schwind 1995, Kriska et al. 1998). Neither males nor females seek flowers or feed during their brief adult life of usually only a couple of days for most species. The functional capabilities of their photoreceptors are, thus, expected to show adaptations to meet the different visual tasks.

Numerous authors have studied optical and physiological characteristics of insect eyes, but few (Butler et al. 1970; Sherk 1977, 1978a,b,c; Cloarec 1980, 1984; Sakamoto et al. 1998) have analysed the morphological changes that occur from hatching to adulthood. What makes members of the mayfly family Baetidae special amongst the insects is that many species exhibit an extraordinary sexual dimorphism in their compound eyes: the males possess two large 'turbanate' dorsal eyes and two smaller lateral eyes, whereas the females possess only the two lateral eyes (Zimmer 1898, Streble 1960, Meyer-Rochow 1971, Horridge \& McLean 1978, Burghause 1981, Horridge et al 1982). A set of three ocelli is present in both sexes.

Perhaps understandably, the huge dorsal eyes of the males have received considerably more attention than the lateral eyes (see review on ephemeropteran eyes by Arvy and Brittain 1984). It is known, for instance, that they contain almost no screening pigment (Burghause 1981), that photomechanical changes upon dark/light adaptation do not occur (Wolburg-Buchholz 1976, Burghause 1981) and that they are sensitive to ultraviolet radiation (Meyer-Rochow 1981, Horridge et al.
1982). In many respects, and this was first noticed by Burghause (1977), they resemble the socalled "dorsal rim ommatidia" known from other insects. The similarity appears particularly strong with the dragonfly eye's so-called "X-region" (Sakamoto et al. 1998). The present paper, however, has little to add to the question of the dorsal eyes, but focuses instead on the less well studied lateral eyes.

\section{Materials and Methods}

Larvae of Cloeon sp. were collectd from Ward Lake, Shillong (25 $34^{\prime} \mathrm{N}$; $\left.91^{\circ} 52^{\prime} \mathrm{E}\right)$. They were sorted into different developmental stages on the basis of wingpad development (Clifford 1970). Thus, larvae lacking wingpads were designated as stage 1, those having wingpads shorter than the distance separating the two wingpads were designated stage 2, while stage 3 larvae had wingpads longer than the aforementioned distance. Those with dark wingpads were designated as stage 4 . At this stage of development, male and female individuals were also distinguishable by the presence or absence of the dorsal eye and by their genitalia.

Subimagines were obtained by rearing nymphs in wellaerated aquaria, and imagines by further maintaining the subimagines in rearing boxes to get the imaginal moult. Because of the soft cuticle of in particular the subimagines and imagines, we used a rather unconventional SEM preparation method: all specimens were fixed for $2-4$ hrs in $2.5 \%$ glutaraldehyde buffered with $0.1 \mathrm{M} \mathrm{Na-cacodylate.} \mathrm{This} \mathrm{was} \mathrm{then}$ followed by washing in buffer, post-fixation in $1 \%$ osmium tetroxide, dehydration in a graded concentration of acetone, and drying by 'Critical Point Drying' apparatus. Several heads were mounted on brass stubs and coated with gold in a 'finecoat ion sputter' JFC 1100 . Observations were made in a SEM (JSM 35CF), operated at $15 \mathrm{kV}$. Photomicrographs of the lateral eyes of 10 male and 10 female Cloeon sp. at each developmental stage were taken. Total comeal surface areas of the eyes and facet sizes of different developmental stages were measured from the photomicrographs. Where it was impossible to count the total number of ommatidia from the micrographs, the average size of one facet was calculated from 10 randomly chosen facets; total corneal surface area of the whole eye was then divided by this value to give the facet count (Meyer-Rochow et al. 1990). This method works well, but cannot be used in cases where facet diameters vary greatly in different parts of the eye. It was, therefore, used only when we dealt with eyes that had not yet differentiated into lateral and dorsal moieties. Statistical analyses like 'Student's t-test', were carried out to see whether the differences between various parameters were significant or not (Zar 1974). Facet diameter was defined as the longest diagonal distance on the outer surface of a facet. Outer comeal convexities, although recognized by us as important and changing during the development, could not be reliably measured from the scanning electron micrographs. 


\section{Results}

\subsection{Lateral eye, female}

Stage 1 nymphs possess only two symmetrical lateral compound eyes, which are not fully developed, having ommatidia with considerable interommatidial spaces (Fig.1). At stage 2 the lateral eyes are much more pronounced and newly formed ommatidia are roughly squarish in outline while ommatidia in the more central and lateral areas are hexagonal in shape. From stage 1 to 2 there is a significant increment of facet size, facet count, and total corneal surface area while from stage 2 to 3 facet size and corneal surface area alone increase significantly with facet count remaining basically the same as before. A similar trend is observed at stage 4 . Ommatidia at this stage are clearly divisible into squarish facets in the dorsal and forward-looking regions, and hexagonal ones at the sides and the periphery (Fig. 2). After the larval transformation into the subimago, there is a significant reduction in ommatidial size accompanied by a corresponding significant increase in the total number of facets. Although the total corneal surface area of the eye

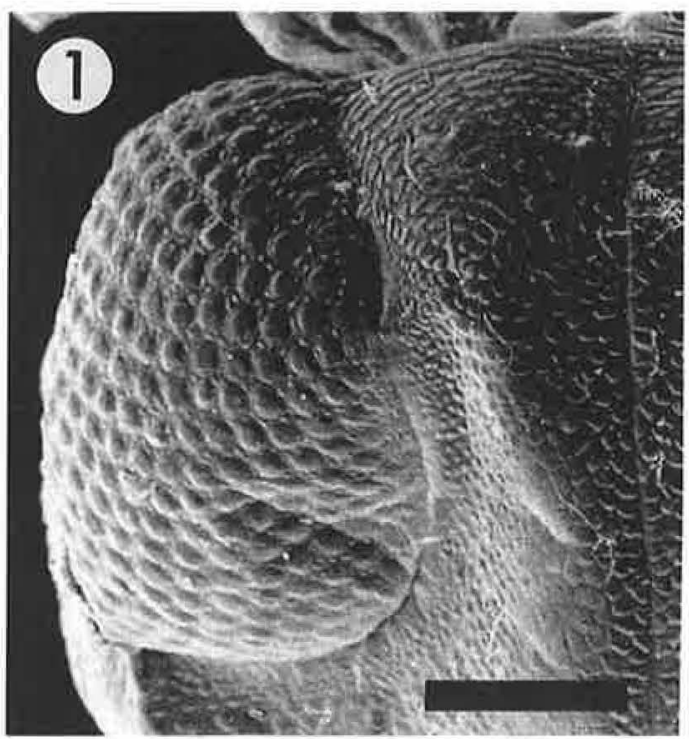

Fig. 1. Lateral eye of female, $1^{\text {st }}$ stage larva. Bar $=50$ $\mathrm{mm}$.

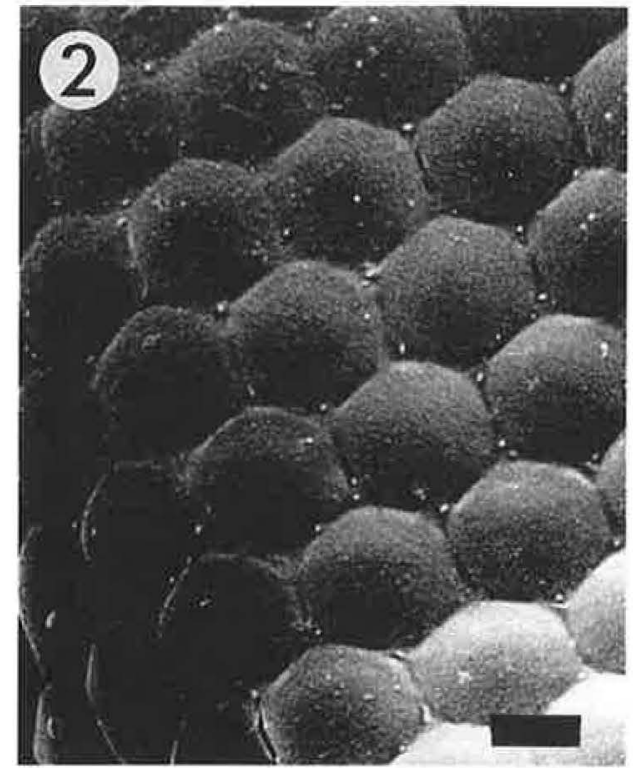

Fig. 2. Lateral eye of female (magnified), $4^{\text {th }}$ stage larva. Bar $=10 \mathrm{~mm}$.

records a marginal decrease, this is not found to be statistically significant (t-test). At this stage squarish ommatidia seem to predominate. After the subimaginal moult, the lateral eyes of the imago register a significant increase in total number of facets and total corneal surface area while changes in facet size are not significant and overall squarish facets are more common (Fig. 3 -5).

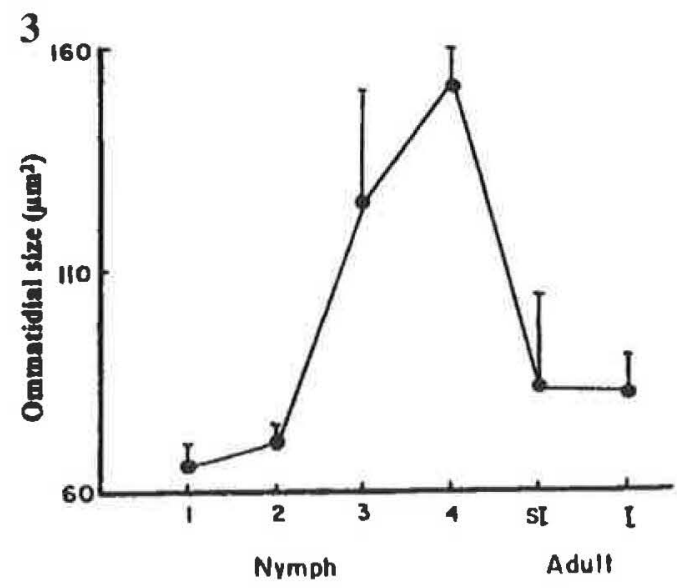

Figs. 3-5. The compound eye of the female. Vertical bars represent standard deviation.

Fig. 3. Mean ommatidial sizes in lateral eyes of female $1^{\text {st }}$ stage larvae through to imago. 
4

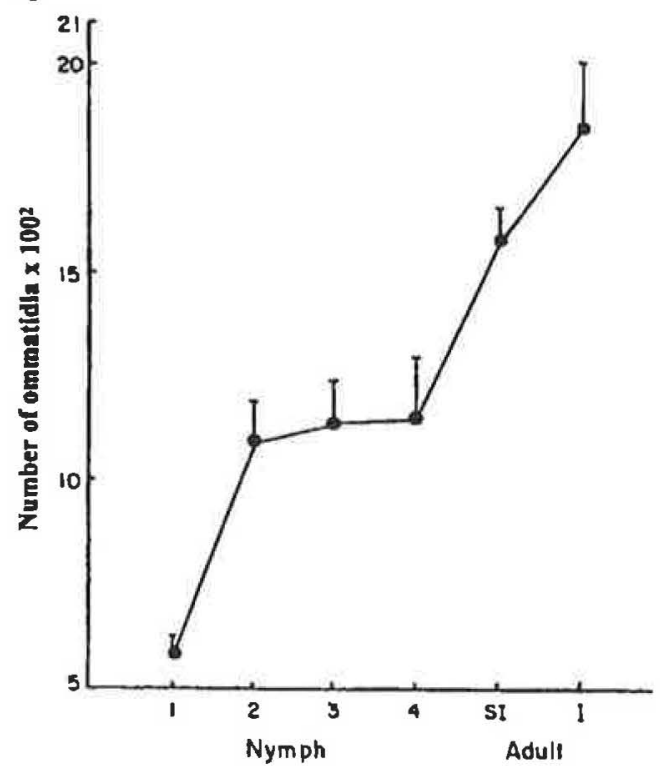

Fig. 4. Mean total number of ommatidia in lateral eyes of female $1^{\text {st }}$ stage larvae through to imago.

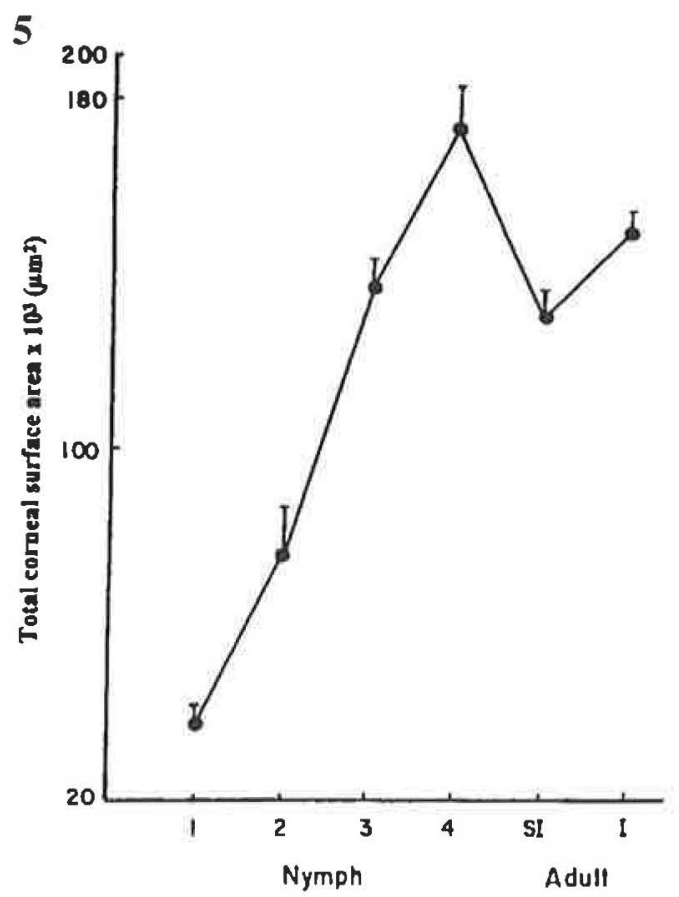

Fig. 5. Means of total corneal surface area in lateral eyes of female $1^{\text {st }}$ stage larvae through to imago.

\subsection{Lateral eye, male}

Male larvae are detected by the presence of the dorsal eyes which are first discernible at stage 2 . From stage 1 to 2 there is no significant difference in the size of the ommatidia while total number of ommatidia and total corneal surface area increase significantly. At stage 3 the developing dorsal eye appears to push the lateral eye towards the outer margin of the head and all the three monitored parameters reveal an increasing trend. A similar trend is observed at stage 4. In contrast, after the larval emergence to the subimago when the dorsal eye has divorced itself from the lateral eye, the latter exhibits significant reductions for all three parameters monitored and that same trend is repeated at the final moult to the imago (Fig. 6-8).

\subsection{Comparison of the lateral eyes of male and female}

At stage 2 facet count and corneal surface area are significantly larger in the female, but facet size

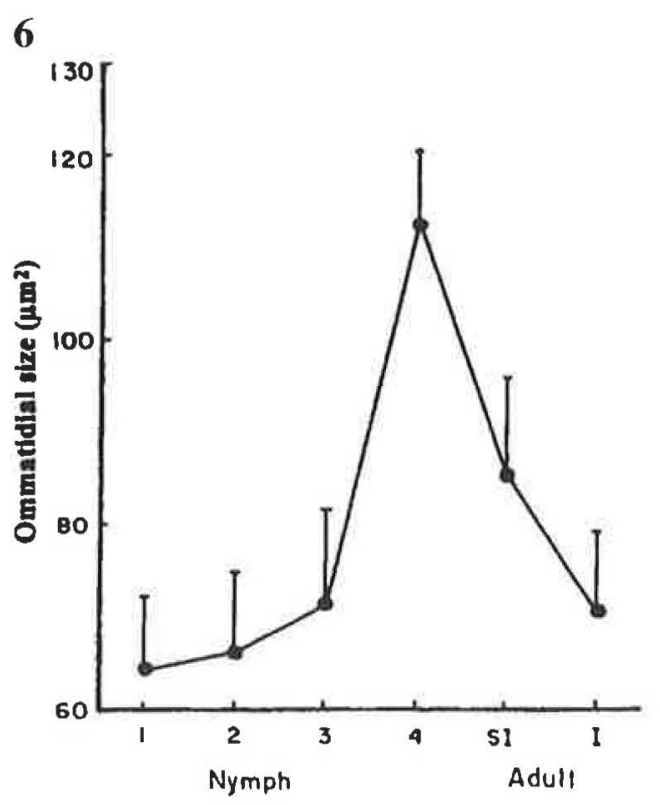

Figs. 6-8. The lateral compound eye of the male. Vertical bars represent standard deviation.

Fig. 6. Mean ommatidial sizes of ommatidia in lateral eyes of male $1^{\text {st }}$ stage larvae through to imago. 


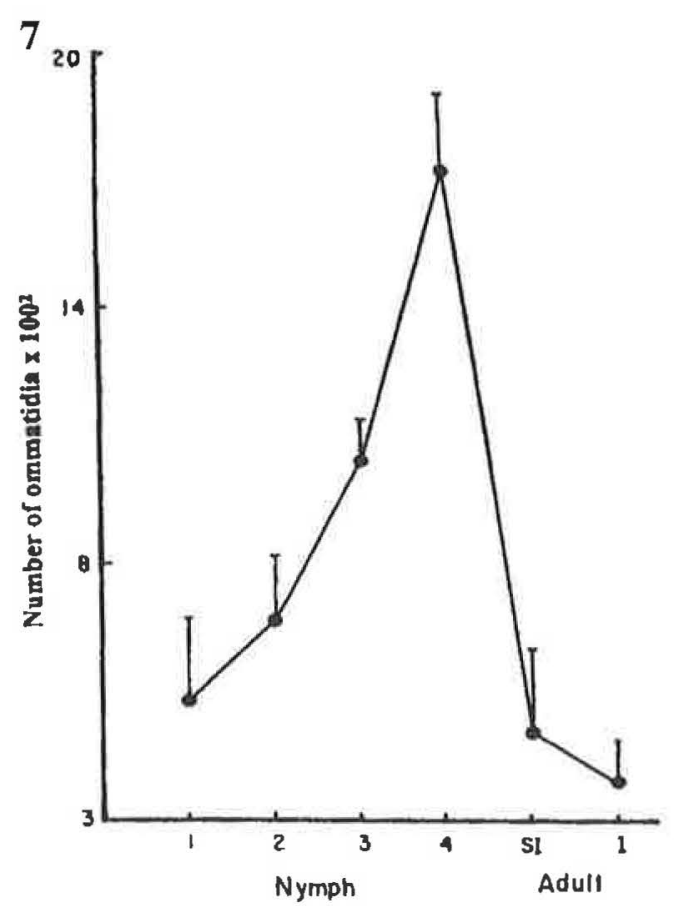

Fig. 7. Mean total number of ommatidia in lateral eyes of male $1^{\text {st }}$ stage larvae through to imago.

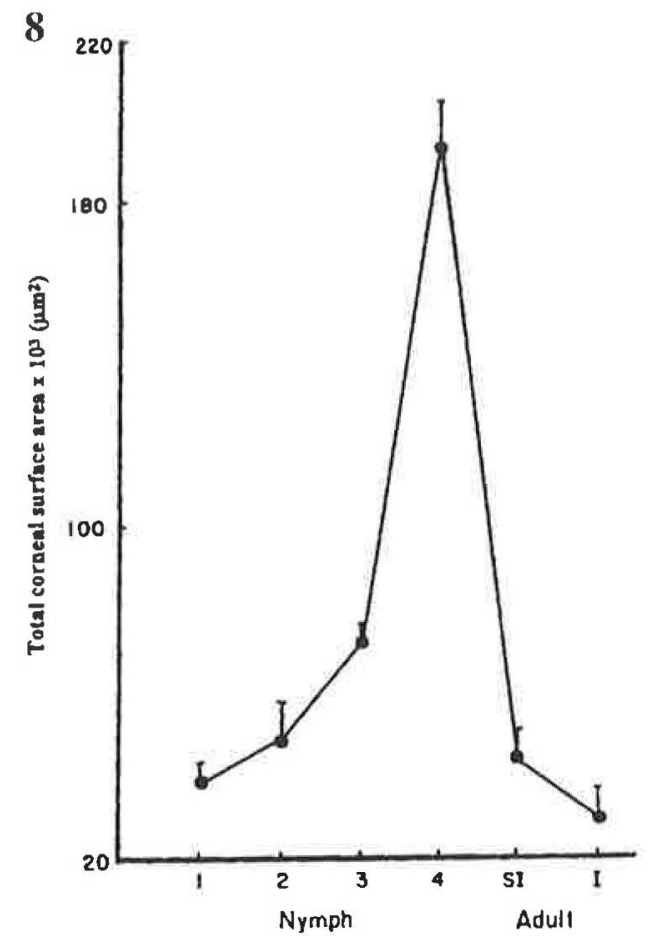

Fig. 8. Means of total corneal surface area in lateral eyes of male $1^{\text {st }}$ stage larvae through to imago. does not show any significant difference. At stage 3 , however, facet size is larger in the female with facet counts remaining the same. Corneal surface area remains larger in female nymphs. At stage 4 corneal surface area does not show any significant difference between male and female nymphs unlike during previous stages. At this stage females have a larger facet size while males have a greater number of facets. At the subimago stage, the corneal surface areas as well as total number of the ommatidia in the lateral eyes are both higher in females, but mean ommatidial size is more or less equal in the two sexes. A similar trend is followed in the imago: females have bigger lateral eyes than males. The findings are summarized together with their statistical significance parameters in Table 1.

\section{Discussion}

Major changes in the external morphology and biometrics of the lateral eyes affect the relative abundance of squarish and hexagonal facets, as well as the size of individual ommatidia, total number of ommatidia and total corneal surface area of the eye. The differences between developing lateral eyes of males and females become more and more apparent as the nymphs approach the final moults and get ready to leave the water, suggesting different visual tasks in the adult.

The post-embryonic development of the lateral eye of both males and females during $1^{\text {st }}$ to $4^{\text {th }}$ nymphal stages follows the same basic pattern with few differences. Mean facet size is somewhat smaller, and facet count somewhat higher in males as compared with females in most nymphal stages while the surface area is generally larger in the female (Table 1). The distinctly different trend shown by the subimago and imago as compared with the nymphs is probably in response to the transition from an aquatic to a terrestrial medium. In the latter the eyes, understandably, have to function in an entirely new photic environment with patterns that move across the visual field in different ways from those in the water, obviously requiring different spatial and temporal sensitivities (Sherk 1978c). Furthermore, after emergence, air no longer offers any colour filtration as done in the water by the chlorophyll of the phytoplank- 
Table 1. Measurements and statistical analysis of ommatidia from male and female Cloeon throughout post-embryonic development.

\begin{tabular}{|c|c|c|c|c|c|c|c|c|c|c|c|c|}
\hline \multirow[b]{2}{*}{ Comparison } & \multicolumn{4}{|c|}{ Size of Ommatidia } & \multicolumn{4}{|c|}{ Total number of ommatidia } & \multicolumn{4}{|c|}{ Corneal surface area } \\
\hline & t-test & df & $P$ & Result & t-test & df & $P$ & Result & t-test & df & $\mathrm{P}$ & Result \\
\hline $2 f$ vs $2 \mathrm{~m}$ & 1.03 & 9 & Ns & $2 f=2 m$ & 6.7 & 11 & 0.001 & $2 f>2 m$ & 5.47 & 12 & 0.001 & $2 l>2 m$ \\
\hline $3 f$ vs $3 \mathrm{~m}$ & 5.68 & 9 & 0.001 & $3 \mathrm{f}=3 \mathrm{~m}$ & 1.22 & 9 & Ns & $3 \mathrm{f}=3 \mathrm{~m}$ & 4.43 & 8 & 0.01 & $31>3 m$ \\
\hline $4 f$ vs $4 \mathrm{~m}$ & 6.65 & 11 & 0.001 & $4 f=4 m$ & 7.35 & 8 & 0.001 & $4 m>4 f$ & 0.68 & 8 & Ns & $4 f>4 m$ \\
\hline Subf vs Subm & 0.25 & 14 & Ns & Subf=Subm & 25.99 & 12 & 0.001 & Subf>Subm & 17,03 & 10 & 0.001 & Subf>Subm \\
\hline $\operatorname{Imf}$ vs Imm & 1.60 & 20 & ns & $\mathrm{Imf}=\mathrm{Imm}$ & 22.80 & 13 & 0.001 & $\mid m f>1 m m$ & 8.30 & 10 & 0.001 & $|\mathrm{~m}|>1 \mathrm{~mm}$ \\
\hline
\end{tabular}

Explanations: $N s=$ not significant; $\mathrm{P}=$ probability; $\mathrm{df}=$ degree of freedom

$2 f, 3 f, 4 f=2^{\text {nd }}, 3^{\text {rd }}, 4^{\text {th }}$ stage females; $2 m, 3 m, 4 m=2^{\text {nd }}, 3^{\text {rd }}, 4^{\text {th }}$ stage males

Subf, Subm = subimago female and male; Imf, Imm = imago female and male

ton, the suspended and dissolved material in the water, and by the water itself, which selectively reduces the intensity of certain wavelengths such as the ultraviolet and infrared (James \& Birge 1938, Whitney 1938a,b, Tyler \& Smith 1970).

The functional problems posed by the transition from water to air are especially acute for female nymphs of Cloeon sp., for not only do they have to fly to find a mate, they are also obliged to locate a suitable water body to lay their eggs once having completed the mating process. They possess only one pair of lateral eyes unlike the males which possess the additional pair of dorsal eyes, although with regard to total body size there is no difference between the two sexes. The deficiency in the females of lacking the large dorsal eyes appears to be, at least partially, overcome by reduced individual facet size along with a concomittant increase in ommatidial number. Hence, in the larvae, a relatively small number of ommatidia view the same visual field that is seen by a much larger number in the subimago and imago. This suggests a greater need to see fine detail once the insect has left the water. It has been shown by several workers (Barlow 1952, Sherk 1977) that a decrease in interommatidial angles leads to improvements in visual resolution, provided the number of ommatidia increases while shape and size of the eye basically remain the same. This is, indeed, the situation encountered in Cloeon sp. females.

The progressive reduction in facet size, facet count, and total corneal surface area in males is apparently due to the tremendous increase in the dimensions of the dorsal eye (Table 1), diminishing the overall importance of the lateral eyes in their visual role, but perhaps preparing them for a more specialized task. The decrease in size of the lateral eye in males following the final two moults need not necessarily mean that now less light enters the eye; individual facets could exhibit much greater convexities of their corneal surfaces in the imago, allowing them to sample light from a wider area. Resolving power of the eye, however, would suffer. The preponderance of hexagonal facets in the curved periphery (compared with the perfectly square facets of the flatter dorsal eyes) is most likely a consequence of (a) the difficulty of packing perfect squares on a curved surface (Ball et al. 1986) and (b) the fact that hexagons are the most economic system of packing maximum number of units (Land 1980, 1981). It may also be a reflection of the way that even square facets evolve from hexagonal ones (Land 1980). Square facets are characteristic of reflecting superposition eyes while refracting superposition eyes have hexagonal facets (Land 1980, 1981). Yet irrespective of whether the superposition is caused by refraction or reflection, both kinds of eye are known to be more efficient in nocturnal/ scotopic vision than apposition eyes, which are characteristic of diurnal/photopic vision (Exner 1891, Land 1980, 1981). Hence, the curved peripheral areas of the lateral eye, being anatomically apposition in nature in both male and female (Meyer-Rochow 1973, Burghause 1981), appear to be largely photopic in function.

According to Fischer (1991), males of the family Baetidae aggregate in swarms, in which they perform non-synchronized vertical dances. They pursue anything flying overhead that vaguely resembles a female (i.e. females of the wrong spe- 
cies, other insects, even birds (!(Fischer, pers. comm.)). Apparently to reduce the probability of chasing a conspecific male and wasting energy, males keep a 'lateral eye' on each other, while at the same time peering upward with their highly enlarged, powerfully sensitive dorsal eyes, which are known to respond to UV-radiation (MeyerRochow 1981, Horridge et al. 1982). The overlap of the visual fields of the two dorsal eyes should allow them to estimate distance: cf. Collett (1998).

The lateral eye undoubtedly needs to have a certain amount of spatial and temporal resolution, so as to help the dancing males avoid collisions between neighbouring dancing males. At the same time the dorsal eye needs to detect moving females against a background, often rich in UV-radiation, but low in overall intensity (most mayflies dance in twilight). Whether or not the males depend on the lateral eye when pursuing a female at close range, remains to be demonstrated, but it would seem likely. The male, therefore, has to blend overall light sensitivity with high flicker fusion frequency and acuity, a combination that according to Horridge et al. (1982) could have resulted in the evolution of light-guides in the dorsal eye of at least the males of the baetid genus Atalophlebia. In any case, a partition of the eye into regions of special tasks and abilities, not unlike those shown to exist in the bee eye (Lehrer 1998), appears to have taken place very early in the evolution of the insect compound eye, but in a much cruder and more obvious way.

Flight behaviour in females of the family $\mathrm{Ba}$ etidae is not very different from that of the males, but speed and direction may vary and zig-zag components (perhaps a procedure to extract depth information from motion parallax: Voss and Zeil 1998) have been observed (Fischer 1991). It is generally assumed that females, entering a swarm of males and performing offering flights, detect swarming males visually and that males (see above) also recognize females by sight. We do not know if that applies to all mayflies or whether there are some species in which mating can occur in darkness or with damaged eyesight; yet, on the basis of sexually dimorphic sensilla we do not want to rule out a pheromonal component totally (Gupta et al. 1999). In the common scenario the male, as soon as it has spotted a female, pursues her and mates. Whether the female has much choice in the matter is not known, but it is an intriguing idea that she might harbour a preference for males with large eyes in the same way as females of stalk-eyed flies choose their male partners with the widest eye-span (Wilkinson et al. 1998). Following matings, the females have to find a suitable body of water to lay their eggs in. They do that on the basis of partially and horizontally polarized light from dark, shiny surfaces, e.g. brownish lakes and streams. It was shown that they may find asphalt roads more attractive than water (Kriska et al. 1998), for unlike most other aquatic insects in which the sensitivity maximum of the polarization system lies in the UV, that of baetid mayflies lies in the region of longer wavelengths (Schwind 1995). The fact that even in the lateral eye of the female areas with either predominantly hexagonal or squarish facets occur, suggests that some regional specialization has taken place despite the lack of a separate dorsal eye. To what extent and for what purpose the female uses the different eye regions is unknown. An intriguing but as yet untested idea is that female baetids choose males with the largest dorsal eyes (see above). This kind of sexual selection has been shown to be of importance at least in stalked eye flies (Wilkinson et al. 1998).

What we can say with confidence in conclusion is that the lateral eyes in baetid larvae, adult males and females not only differ morphologically, but face quite different functional tasks as well. We can provide reasons for some of the differences like the larger number of facets and the smaller interommatidial angles in the lateral eyes of the females, but, like others before us, we are unable to explain why a portion of only the male larval eye becomes transformed into perfectly square facets upon maturation.

Acknowledgements. The authors wish to thank Professor Dr. D.T. Khathing, Head of Regional Sophisticated Instrumentation Centre, North-Eastern Hill University (NEHU) for his help and encouragement and V.B.M-R. is grateful to NEHU for the financial and logistic support received during his sabbatical stay in Shillong.

\section{References}

Arvy, L. \& Brittain, J. E. 1984: The structure, function and development of the eyes in the Ephemeroptera. - Proc. 
4th Int. Conf. Ephemeroptera: 173-179.

Ball, E. E., Stone L. C., \& Land M. F. 1986: Eye structure and optic in the pelagic shrimp Acetes sibogae (Decapoda, Natantia, Sergestidae) in relation to light dark adaptation and natural history. - Phil. Trans. Roy. Soc. Lond. B 313: 251-270.

Barlow, H. B. 1952: The size of ommatidia in apposition eyes. - J. Exp. Biol. 29: 667-674.

Burghause, F. 1977: Neue Ergebnisse an Doppelaugen von Insekten. - Sitzber. Ges. Naturforsch. Freunde Berlin NF 17: 137-143.

Burghause, F. 1981: The structure of the double-eyes of $\mathrm{Ba}$ etis and the uniform eyes of Ecdyonurus (Ephemeroptera). - Zoomorphology 98: 17-34.

Butler, L., Roppel, R., \& Zeigler, J. 1970: Post emergence maturation of the eye of the adult carpet beetle, Attagenus megatoma (Fab.): an electron microscope study. J. Morphol. 130: 103-128.

Clifford, H. F. 1970: Analysis of a northern mayfly population, with special reference to allometry of size. - Can. J. Zool. 48: 305-316.

Cloarec, A. 1980: Ontogeny of hit distance estimation in Ranatra. - Biol. Behav. 5: 97-118.

Cloarec, A. 1984: Development of the compound eyes of the water stick insect Ranatra linearis. - Physiol. Entomol. 9: 253-262.

Collett, T. S. 1996: Vision: simple stereopsis. - Curr. Biol. 6: $1392-1395$

Cummins, K. W. 1973: Trophic relations of aquatic insects. - Annu. Rev. Entomol. 18: 183-206.

Exner, S. 1891: Die Physiologie der facettirten Augen von Krebsen und Insekten. - Leipzig und Wien, Franz Deuticke.

Fischer, C. 1991: Die Evolution des Schwarmfluges und Flugverhalten der Ephemeropteren. - Ph.D.-Dissertation, Univers. Erlangen-Nümberg, 171 pp.

Gupta, S., Gupta, A. \& Meyer-Rochow, V. B. 1999: Cuticular microstructures of abdominal tergites and sternites of Cloeon sp. (Ephemeroptera; Baetidae) during postembryonic development. - Entomol. Fennica 10: 51 59.

Horridge, G. A. \& McLean, M. 1978: The dorsal eye of the mayfly Atalophlebia (Ephemeroptera). - Proc. Roy. Soc. Lond. B 200: 137-150.

Horridge, G. A., Marcelja, L. \& Jahnke, R. 1982: The dorsal eye of the mayfly Atalophlebia (Ephemeroptera). Proc. Roy. Soc. London B 216: 25-51.

James, H. R. \& Birge, E. A. 1938: A laboratory study of the absorption of light by lake waters. - Trans. Wisc. Acad. Sci. (Arts and lit.) 31: 2-48.

Kriska, G., Horvath, G., \& Andrikovics, S. 1998: Why do mayflies lay their eggs en masse on dry asphalt roads? Water-imitating polarized light reflected from asphalt attracts Ephemeroptera. — J. Exp. Biol. 201: 2273-2286.

Land, M. F. 1980: Compound eyes:old and new optical mechanisms. - Nature 287: 681-686.

Land, M. F. 1981: Optics and vision in invertebrates. - In: Autrum H. (ed.) Handbook of sensory physiology, vol. VII/6b. Springer, Berlin, VII/66: 471-492.

Lehrer, M. 1998: Looking all around: Honeybees use different cues in different eye regions. - J. Exp. Biol. 201: 3275-3292.
Merritt, R. W., Cummins, K. W. \& Burton, T. M. 1984: The role of aquatic insects in the processing and cycling of nutrients. - In: Resh, V.H. \& Rosenberg, D.M. (eds.), The ecology of aquatic insects: 134-163. Praeger, New York.

Meyer-Rochow, V. B. 1971: Fixierung von Insektenorganen mit Hilfe eines Netzmittels. Das Dorsalauge der Eintagsfliege Atalophlebia costalis. - Mikrokosmos 60: 348352.

Meyer-Rochow, V. B. 1973: The eyes of nocturnal insects. Ph.D. - Dissertation, Austral. Natl. Univ., Canberra, 299 pp.

Meyer-Rochow, V. B. 1981: Electrophysiological studies of the insect compound eye. - N Zld Entomologist 7: 296304.

Meyer-Rochow, V. B., Towers, D. \& Ziedins, I. 1990: Growth patterns in the eye of Petrolisthes elongatus (Crustacea, Decapoda, Anomura). - Exp. Biol. 48: 329-340.

Sakamoto, K., Seki, T., Koseki, S., Kashiwagi, T. \& Eguchi, E. 1998: Comparative studies on compound eyes of larvae and adults of an aeschnid dragonfly, Anax nigrofasciatus nigrofasciatus (I) Dorsal part. — Int. J. Odonatology 1: 15-31.

Schwind, R. 1995: Spectral regions in which aquatic insects see reflected light. - J. Comp. Physiol. 177: 439-448.

Sherk, T. E. 1977: Development of the compound eyes of dragonflies (Odonata). I. Larval compound eyes. - J. Exp. Zool. 201: 391-416.

Sherk, T. E. 1978a: Development of the compound eyes of dragonflies (Odonata). II. Development of the larval compound eyes. - J. Exp. Zool. 203: 47-60.

Sherk, T. E. 1978b: Development of the compound eyes of dragonflies (Odonata). III. Adult compound eyes. - J. Exp. Zool. 203: 61-80.

Sherk, T. E. 1978c: Development of the compound eyes of dragonflies (Odonata). IV. Development of the adult compound eyes. - J. Exp. Zool. 203: 183-200.

Streble, H. 1960: Die Augen der Eintagsfliege Cloeon dipterum. - Mikrokosmos 49: 237-244.

Tyler, J. E. \& Smith, R. C. 1970: Measurements of spectral irradiance underwater. Gordon and Breach Science Publ., New York.

Voss, R. \& Zeil, J. 1998: Active vision in insects: an analysis of object-directed zig-zag flights in wasps (Odynerus spinipes, Eumenidae). - J Comp Physiol A 182: 377387.

Whitney, L. V. 1938a: Continuous radiation measurements in Wisconsin lakes. - Trans. Wisc. Acad. Sci. (Arts and let.) 31: 175-200.

Whitney, L. V. 1938b: Transmission of solar energy and scattering produced by suspensoids in lake water. - Trans. Wisc. Acad. Sci. (Arts and let.) 31: 201-213.

Wilkinson, G. S., Presgraves, D. C. \& Crymes, L. 1998: Male eye span in stalk-eyed flies indicates genetic quality by meiotic drive suppression. - Nature 391: 276-279.

Wolburg-Buchholz, K. 1976: The dorsl eye of Cloeon dipterum (Ephemeroptera). — Z. Naturforsch. 31c: 379393.

Zar, J. H. 1974: Biostatistical analysis. — Prentice-Hall Inc., New Jersey.

Zimmer, C. 1898: Die Facettenaugen der Ephemeriden. Z. Wiss. Zool. 63: 236-261. 